\title{
QUINZE ANOS DA AGÊNCIA NACIONAL DE SAÚDE (ANS): ANÁLISE DO EIXO ESTRATÉGICO DE ARTICULAÇÃO E APRIMORAMENTO INSTITUCIONAL NA PERCEPÇÃO DOS ESPECIALISTAS
}

\section{RESUMO}

Este artigo analisa em que medida a Agência Nacional de Saúde - ANS vem alcançando os objetivos estratégicos traçados na sua criação com foco no aprimoramento e articulação institucional. A metodologia utilizada foi qualitativa construída com base na técnica Delphi, onde a percepção de 12 especialistas foi analisada e avaliou-se as relações com públicos de interesse, transparência nas informações e aprimoramento da capacidade regulatória. Os resultados evidenciam que a ANS vem beneficiando a sociedade com maior controle das operadoras, qualidade dos serviços, padronização das coberturas mínimas e reajustes máximos. No entanto, os achados da pesquisa também demonstram que falta à ANS: i) agilidade para analisar e julgar reclamações e multar planos de saúde, ii) eficiência nos processos, iii) equilíbrio dos interesses dos públicos-alvo e, iv) melhoria na comunicação com a sociedade para alcançar uma regulação mais objetiva e transparente.

Palavras-chave: ANS; Eixos Estratégicos; Regulação do Setor de Saúde; Estratégia na Gestão Pública.

\section{FIFTEEN YEARS OF THE NATIONAL HEALTH AGENCY (ANS): STRATEGIC AXIS ANALYSIS OF THE INSTITUTIONAL ARTICULATION AND IMPROVEMENT FROM THE EXPERTS' PERSPECTIVE}

\begin{abstract}
This article analyzes the extent to which the National Health Agency - ANS has achieved the strategic goals established in its creation with a focus on improvement and institutional articulation. The methodology was qualitative built using the Delphi technique, we analyzed and evaluated the perception of 12 experts about relationships with stakeholders, information transparency and regulatory capacity improvement. The results show that the ANS has benefited society with greater operators control, service quality, standardization of minimum coverage and maximum price increases. However, it also revealed that ANS lacks: i) flexibility to analyze and judge complaints and fine health plans, ii) efficiency in processes, iii) balance of stakeholders' interests and, iv) improved communication with society to achieve a more objective and transparent regulation.
\end{abstract}

Keywords: ANS; Strategic Axis; Regulation of the Health Sector; Public Administration Strategy. 
Quinze Anos da Agência Nacional de Saúde (ANS): Análise do Eixo Estratégico de Articulação e Aprimoramento Institucional na Percepção dos Especialistas

\title{
QUINCE AÑOS DE AGENCIA NACIONAL DE SALUD (ANS): ANÁLISIS DE CONJUNTO EJE ESTRATÉGICO Y MEJORA INSTITUCIONAL EN LA PERCEPCIÓN DE EXPERTOS
}

\section{RESUMEN}

En este artículo se analiza en qué medida la Agencia Nacional de Salud - ANS ha alcanzado los objetivos estratégicos descritos en su creación con un enfoque en la mejora y articulación institucional. La metodología cualitativa fue construido en la técnica Delphi, donde se analizó la percepción de 12 expertos y evaluado las relaciones con las partes interesadas, la transparencia de la información y mejorar la capacidad de regulación. Los resultados muestran que la NSA se ha beneficiado de la sociedad con un mayor control de los operadores, la calidad del servicio, la normalización de cobertura mínima y los ajustes máximos. Sin embargo, los resultados de la encuesta también muestran que carecen de la ANS: i) la flexibilidad para analizar y juzgar las quejas y planes de salud finas, ii) la eficiencia en los procesos, iii) equilibrio de intereses audiencias y, iv) la mejora de la comunicación con la sociedad para lograr una regulación más objetiva y transparente.

Palabras clave: ANS; Ejes estratégicos; Regulación del Sector Salud; Estrategia en la Gestión Pública.

\author{
Fernando Filardi ${ }^{1}$ \\ Angilberto Sabino Freitas ${ }^{2}$ \\ Helio Arthur Irigaray ${ }^{3}$ \\ Luciene Capra ${ }^{4}$
}

\footnotetext{
${ }^{1}$ Doutor em Administração pela Universidade de São Paulo - USP. Professor do Mestrado Administração do Grupo IBMEC. Brasil. E-mail: fernandofilardi@gmail.com

2 Doutorado em Administração de Empresas pela Pontifícia Universidade Católica do Rio de Janeiro - PUC/RJ. Professor da Universidade do Grande Rio - UNIGRANRIO. Brasil. E-mail: angilberto.freitas@ gmail.com

${ }_{3}^{3}$ Doutor em Administração de Empresas pela Escola de Administração de Empresas da Fundação Getulio Vargas EAESP/FGV. Brasil. E-mail: helio.irigaray@fgv.br

4 Mestranda em Administração pela Universidade do Grande Rio - UNIGRANRIO. Brasil. E-mail: lucapra@hotmail.com
} 


\section{INTRODUÇÃO}

Com o objetivo de complementar a saúde pública prestada pelo Estado, entre as décadas de 1940 e 50, foram criados os primeiros planos de saúde da rede privada de saúde suplementar no Brasil, os quais, durante muito tempo, funcionaram sem qualquer regulação, impondo aos beneficiários as regras e valores de mercado que esses julgassem pertinentes.

Por outro lado, com as alterações no papel do Estado, iniciadas na década de 80, baseadas em um modelo mais enxuto chamado New Public Management (Nova Gestão Pública), em que se busca uma maior eficiência dos processos públicos (Goldfinch e Wallis, 2010), inicia-se um movimento de redução da presença do estado na economia que levou Bresser-Pereira (1996) a analisar os aspectos essenciais da reforma administrativa proposta como resposta à crise do Estado e ao processo de globalização da economia mundial, ficando o Estado apenas com o papel de regular o mercado.

Nesse sentido, a Constituição de 1988 estabeleceu o primeiro marco regulatório do setor no país, o qual estruturou o sistema nacional de saúde por meio da criação do Sistema Único de Saúde (SUS). Dez anos depois, foi aprovada a Lei $n^{\circ} 9656$ (1998), conhecida como o segundo marco regulatório brasileiro, que define o que são planos e seguros privados de assistência à saúde, bem como suas obrigações, área de atuação e subordinação ao Conselho de Saúde Suplementar (CONSU).

Assim, seguindo os princípios de que o Estado deve regular as atividades de forma eficaz, deu-se a criação de Agências Reguladoras, que, de acordo com Filardi (2000), tinham o intuito de regular e intervir em setores da economia que eram responsabilidade do governo, mas estavam em processo de transferência para o setor privado.

Seguiu-se então em 2000 com a criação da Agência Nacional de Saúde Suplementar (ANS), através da Lei no 9.961 (2000), cuja missão é promover a defesa do interesse público no que tange à saúde suplementar, regulando, fiscalizando, controlando e normatizando as atividades do setor e as operadoras de saúde, bem como suas relações com prestadores e beneficiários. Para isso foram criados quatro eixos estratégicos institucionais para direcionar a atuação da agência na trajetória rumo ao cumprimento de sua missão: (1) Qualificação de Saúde Suplementar; (2) Sustentabilidade do Mercado; (3) Articulação e Aprimoramento Institucional; e (4) Desenvolvimento Institucional.

Devido a importância do eixo estratégico de Articulação e Aprimoramento Institucional junto ao público externo, esse eixo foi escolhido como objeto deste estudo uma vez que ele trata da relação com a sociedade, da criação de massa crítica para o setor e da regulação dos mercados. Além disto, contempla a avaliação dos atores externos sobre o desempenho e a efetividade da Agência, conforme descrito no contrato de gestão da ANS (2014).

Assim, a pergunta de investigação que pauta este estudo é: em que medida os objetivos estratégicos propostos no eixo de Articulação e Aprimoramento Institucional estão sendo alcançados? Para respondê-la, realizamos uma pesquisa com especialistas do setor de saúde utilizando o Método Delphi.

\section{MARCO TEÓRICO}

\subsection{As Agências Reguladoras}

Com a reforma do Estado iniciada nos anos 90, reduzindo o tamanho da máquina pública, e com o objetivo de criar condições para garantir a regulamentação e intervenção em diversos setores da economia de forma eficiente, além de fiscalizar as atividades exercidas pelo mercado suplementar, o Estado começou a criar, a partir de 1996, as Agências Reguladoras. (Avelar e Cintra, 2004). Assim, o relacionamento do Estado com o mercado passou a ser centrado nas atividades regulatórias, onde as agências passaram a ter a prerrogativa de legislar as regras de diversos setores (Boschi, 2002). Nesse contexto, a atividade de regulação passou a ser a nova forma de intervenção estatal, impactando diretamente nas relações entre mercado e estado.

Pode-se dizer que as agências são instituições ambivalentes, geralmente criadas quando existem falhas de mercado, que devem ser entendidas como a incapacidade da tomada de decisão, muitas vezes por falta de simetria de informação, decorrente da desigualdade de conhecimento dos dados entre concorrentes de mercado (Souza, 2004). Nesse aspecto, as agências possuem dois objetivos focais que são: (1) preservar o equilíbrio econômico-financeiro dos regulados e; (2) garantir o acesso e a qualidade dos serviços prestados à população (Pinheiro, Monteggia e Aguzzoli, 2000).

\subsection{Modelo Regulatório Brasileiro da Saúde}

Na saúde, o modelo regulatório brasileiro sofreu influências internacionais, principalmente europeia e americana. Enquanto o modelo inglês inspirou a promoção pela harmonia entre os atores que compõem o setor regulatório e o setor público, com foco constante nas relações e na regulação, a experiência americana influenciou a estrutura organizacional, com sua autonomia e descentralização (Costa, 2008).

De forma geral, o modelo regulatório foca no estímulo à competição de mercado, tornando a regulação menos burocrática e formal (Costa, 2008). O mercado de saúde suplementar no Brasil adotou a teoria de oferta e demanda em que o preço é resultante do equilíbrio dessas duas forças. A premissa baseia-se no fundamento de que os produtores ofertam seus serviços por um determinado preço e os usuários adquirem aqueles que se adéquam a 
sua renda e necessidades. Além disto, o princípio da racionalidade permeia o modelo adotado, definindo que o beneficiário sabe exatamente o que necessita, argumentando que em condições de perfeita competição ambos os lados maximizam suas vantagens e interesses (Castro, 2002).

Outro fundamento importante do modelo regulatório brasileiro da saúde suplementar refere-se à geração e disseminação das informações sobre o setor aos consumidores, em que afirma que com base em opções e suas próprias experiências, o beneficiário é perfeitamente capaz de fazer suas escolhas, alavancando, assim, o mercado (Costa, 2008). Nesse modelo, a Agência Reguladora tem o papel fundamental de controlar a propriedade e zelar pelo desempenho das empresas, tudo permeado por uma visão tecnicista e autônoma.

\subsection{O Setor de Saúde e a Saúde Suplementar no Brasil}

A comercialização de planos de saúde para empresas ocorre no Brasil desde a década de 50, sendo naqueles tempos notoriamente ignorada pelos mecanismos de organização do sistema de saúde no país. Seguindo a sua evolução, em meados da década de 80 ocorre a expansão deste nicho para o público individual. Foi na década de 90 que se começou a estruturação do que hoje conhecemos como saúde suplementar, com expressivo aumento de demanda advindo de pequenas empresas e grupos familiares de baixa renda e com a transferência da prestação da saúde da esfera pública para a esfera privada, reduzindo a responsabilidade do poder público de prover um serviço essencial descrito na Carta Magna como uma obrigação constitucional.

Até início dos anos 90, a impressão era de que as funções assumidas pelas empresas privadas substituiriam as obrigações do Estado. Entretanto, as crises econômicas impediram a expansão do mercado por parte das empresas (Nitão, 2004). Assim, as crises econômicas e mazelas sociais logo demonstraram que era necessária uma parceria entre o Estado e a iniciativa privada, para que seus serviços se complementassem. Além disto, era necessário que o Estado criasse em uma forma de manter o controle e a fiscalização sobre as atividades desempenhadas pelo mercado. (Ibañez e Vecina Neto, 2007).

Assim, em 1997 foi aprovada a primeira versão da Lei de Regulamentação dos Planos de Saúde, e, segundo informações constantes na revista Regulação e Saúde da ANS (2004), percebeu-se a imensa dificuldade que, futuramente, o Estado teria para satisfazer os interesses dos atores envolvidos no processo, levando a necessidade de se regular o setor e de criar uma agência reguladora.

\subsection{Criação e Atuação da Agência Nacional de Saúde (ANS)}

Em 2000, criou-se a Agencia Nacional de Saúde (ANS), uma autarquia criada por lei, com personalidade jurídica, patrimônio e receita própria, com o propósito de regular, controlar e fiscalizar a área de saúde suplementar, portanto, uma instituição autônoma (Lei 9.961, 2000), estruturada em cinco áreas distintas: Diretoria de Normas e Habilitação das Operadoras; Diretoria de Normas e Habilitação de Produtos; Diretoria de Fiscalização; Diretoria de Desenvolvimento Setorial; e a Diretoria de Gestão.

Ao contrário de outras agências reguladoras, provenientes de um processo de privatização e/ou desestatização, a ANS foi criada para regular as atividades de um setor que já existia. Sua essência estava na busca da equidade das relações entre os principais atores do setor, o acompanhamento das empresas economicamente, a padronização dos produtos comercializados e a promoção da simetria de informações (Nitão, 2004).

Um dos maiores desafios da ANS nos anos que se seguiram foi o de atuar em um mercado peculiar, tentando impedir a concentração dos planos de saúde, segurar os preços e aumentar a qualidade dos serviços (Salvatori e Ventura, 2012). A complexidade durante esse processo veio da necessária adaptação das empresas a esse novo ambiente, que exigiu novas habilidades e conhecimentos, bem como uma profissionalização ainda maior das empresas que desejassem se manter nesse mercado (Nitão, 2004). Assim, como apontam Ocké-Reis (2005), o desafio da ANS é, diante do interesse público, servir de eixo organizador de um programa de reforma das empresas do mercado de planos de saúde.

Para controlar o desempenho da ANS em todas as suas atividades e atribuições legais, o Governo e a sociedade contam com o contrato de gestão pactuado entre a instituição e o Ministério da Saúde. O instrumento agrupa uma série de indicadores de resultados que permitem o estabelecimento de diretrizes estratégicas de atuação e uma avaliação objetiva quanto ao desempenho da instituição. $O$ primeiro contrato de gestão foi assinado quando da criação da ANS em 2000, e a exceção do contrato assinado em 2002 com vigência bienal, todos os demais tem validade anual, com publicação de relatório de execução e justificativas também anuais.

Dentre as cláusulas mais importantes do contrato de gestão, além dos próprios indicadores, pode-se citar a que trata das penalidades, pois dispõe que o não atendimento aos termos pactuados, sem justificativa cabível e aceita pelo Ministério da Saúde, pode levar a exoneração do corpo de dirigentes da Agência.

Além do contrato de gestão, a sociedade conta ainda com uma ferramenta chamada de Agenda Regulatória, que, segundo definição do próprio site da ANS, "trata-se de um compromisso da Agência". Nesse instrumento é estabelecido um cronograma que contempla atividades consideradas prioritárias à regulação da saúde 
suplementar e que visam proporcionar maior transparência, promovendo "o desenvolvimento saudável e sustentável do setor regulado".

Por fim, como forma de controle interno a ANS conta ainda com indicadores que são pactuados junto a cada diretoria e que visam o acompanhamento das atividades dos seus colaboradores, com acompanhamentos diferenciados. Conforme descrito no Contrato de Gestão da ANS (2006), para ser capaz de cumprir com sua missão institucional, a ANS funciona com base em quatro eixos estratégicos: (1) Qualificação de Saúde Suplementar; (2) Sustentabilidade do Mercado; (3) Articulação e Aprimoramento Institucional; e (4) Desenvolvimento Institucional. Para fins deste estudo, delimitamos a pesquisa ao eixo de Articulação e Aprimoramento Institucional, cujos objetivos declarados são descritos na tabela 1:

Tabela 1 - Objetivos Estratégicos da Agência Nacional de Saúde Suplementar

\begin{tabular}{|l|l|}
\hline Eixo Estratégico & \multicolumn{1}{c|}{ Objetivos Estratégicos } \\
\hline & $\begin{array}{l}\text { Divulgar os resultados para a sociedade } \\
\text { Intensificar o relacionamento com os públicos de interesse, inclusive o interno } \\
\text { Articulação } \\
\text { Aprimoramento } \\
\text { Institucional }\end{array}$ \\
& $\begin{array}{l}\text { Desenvolver parcerias estratégicas para o incremento de projetos e pesquisas } \\
\text { Promover a geração e disseminação de conhecimento no setor } \\
\text { Aprimorar os instrumentos e ferramentas de regulação } \\
\text { Aprimorar capacidade regulatória } \\
\\
\text { Medir e ampliar a efetividade do uso das soluções de TI }\end{array}$ \\
\hline
\end{tabular}

Fonte: ANS - Contrato de Gestão (2006)

Ao avaliar os primeiros anos de atuação da ANS, Santos, Malta e Merhy (2008) apontam alguns resultados da regulação produzida na saúde suplementar no período de 2000 a 2006 sob três eixos analíticos da regulação: (i) estrutura e operação do setor; (ii) a regulação econômica e; (iii) a assistencial. Os resultados apontaram que a regulação implementada trouxe avanços importantes nas três dimensões analisadas. Identificaram uma maior solidez das operadoras e um crescimento do setor da ordem de $30 \%$ no número de beneficiários. Em relação à regulação assistencial, verificou-se a introdução de novas práticas assistências que valorizaram a promoção e a prevenção, além de propor mecanismos de avaliação de qualidade. Entretanto, sugerem que a relação públicoprivado ainda carece de uma maior discussão e que o modelo assistencial ainda precisa avançar para superar a fragmentação existente da saúde no Brasil.

Até hoje, apesar dos seus 15 anos de existência, observa-se que ainda pairam dúvidas, principalmente dos beneficiários, acerca da ANS e sua finalidade. A despeito de não haver dúvidas de que as agências reguladoras representam um avanço, Salvatori e Ventura (2012) apontam desafios a serem enfrentados como monitoramento da qualidade da assistência prestada, a renúncia fiscal, a existência dos cartões de desconto, a operação de empresas como operadoras de planos de saúde sem o registro na ANS e a adoção de alguns mecanismos nocivos de regulação assistencial pelas operadoras. Isso significa que apesar dos avanços que podem ser vistos no setor, ainda há muito que se fazer para um atendimento mais igualitário da saúde no Brasil.

\section{PERCURSO METODOLÓGICO}

Neste estudo, utilizamos o método Delphi, o qual é pertinente para a "identificação de acontecimentos e elementos para uma pesquisa, quando ao invés de reunir opiniões de indivíduos isolados, reúnem-se respostas de especialistas na área estudada" (Delurgio, 1998: 636). Este método é utilizado quando há carência de informações históricas e/ou intenção de promover a inovação, com foco na projeção de tendências (Wright e Giovinazzo, 2012). A técnica de consulta a especialistas do ramo por meio de questionário pode ser repassada inúmeras vezes, até que se encontre consenso nas opiniões, e que as mesmas reflitam o pensamento sobre determinado tema. Durante a pesquisa, mantivemos o sigilo da identidade dos respondentes e qualquer informação que pudesse influenciar as respostas.

Assim, selecionamos especialistas em saúde suplementar para participar da pesquisa e fornecer subsídios para análise dos aspectos ligados às dimensões categorizadas, baseadas nos objetivos estratégicos ligados à articulação e aprimoramento institucional.

$\mathrm{Na}$ ausência de uma definição única e de senso comum sobre o conceito de especialistas, definimos alguns critérios, não excludentes entre si: (1) notório saber; (2) formação acadêmica e especialização em saúde suplementar ou saúde pública; e (3) tempo mínimo de 5 (cinco) anos de atuação em atividades ligadas à saúde suplementar.

A seleção inicial dos potenciais participantes foi realizada a partir de um levantamento baseado em documentos, artigos e livros sobre saúde suplementar, física e virtualmente utilizando bibliotecas de empresas e 
universidades, bases de dados EBSCO, Proquest e Spell, além de páginas da internet, sendo que a lista inicial de especialistas pré-selecionados chegou a mais de 50 profissionais. Estes especialistas foram divididos em grupos e sorteados aleatoriamente buscando um equilíbrio entre os representantes de cada público alvo, conforme descrito acima.

A pesquisa foi iniciada com 4 especialistas que, após serem contatados, se disponibilizaram a responder o questionário. As respostas foram coletadas e tabuladas, e um novo grupo de 4 especialistas foi contatado e se disponibilizou a participar. Novamente as respostas foram coletadas e tabuladas, gerando um conjunto de informações bastante relevante sobre os aspectos abordados. Visando consolidar os dados já coletados, um terceiro grupo de 4 especialistas foi contatado e os questionários foram remetidos, sendo posteriormente coletadas e tabuladas suas respostas e agregadas ao conjunto de informações anteriormente classificado. Nessa fase da pesquisa, a amostra se revelou suficiente e relevante na medida em que foi atingida a saturação das respostas. A pesquisa contemplou, portanto, 12 (doze) especialistas (tabela 2).
A elaboração do questionário foi feita com base no eixo estratégico e nos objetivos estratégicos da ANS ligados à articulação e aprimoramento institucional (tabela 1). Para a definição das questões referentes ao questionário da primeira rodada, um pesquisador especialista em método Delphi e dois especialistas em saúde suplementar, diferentes daqueles que seriam entrevistados, auxiliaram no aprimoramento das questões de forma que se pudesse obter o máximo possível de informações relevantes ao estudo.

O questionário aplicado na primeira rodada foi composto por 14 questões ligadas aos objetivos estratégicos da ANS, sendo 7 blocos de 2 questões para cada objetivo e uma pergunta final que buscou investigar quais deveriam ser as ações da ANS no sentido de se preparar para atuar de maneira mais eficiente e transparente no tocante aos objetivos estratégicos referentes à Articulação e Aprimoramento Institucional. O questionário foi desenvolvido no Forms do Google Drive e enviado por e-mail aos especialistas, garantindo-lhes o anonimato.

Tabela 2 - Perfil dos Especialistas Participantes

\begin{tabular}{|c|c|c|}
\hline ESPECIALISTA & ATIVIDADE ATUAL & $\begin{array}{l}\text { ATUAÇÃO NA SAÚDE } \\
\text { SUPLEMENTAR }\end{array}$ \\
\hline 1 & $\begin{array}{l}\text { Médico e Assessor Especial do Ministério } \\
\text { da Saúde }\end{array}$ & $\begin{array}{l}\text { Atuou junto à saúde suplementar por } \\
\text { mais de } 6 \text { (seis) anos consecutivos }\end{array}$ \\
\hline 2 & $\begin{array}{l}\text { Diretor de Consultoria na Área de } \\
\text { Estatística e Atuária. Especialização em } \\
\text { Saúde Suplementar }\end{array}$ & $\begin{array}{l}\text { Atua há mais de } 5 \text { (cinco) anos junto a } \\
\text { saúde suplementar }\end{array}$ \\
\hline 3 & $\begin{array}{l}\text { Servidor de uma Instituição de Saúde do } \\
\text { Governo }\end{array}$ & $\begin{array}{l}\text { Atuou junto a saúde suplementar por } 8 \\
\text { (oito) anos consecutivos }\end{array}$ \\
\hline 4 & 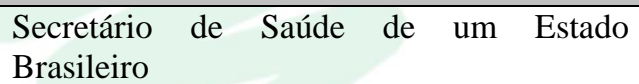 & $\begin{array}{l}\text { Atuou junto à saúde suplementar por } \\
\text { mais de } 7 \text { (sete) anos consecutivos }\end{array}$ \\
\hline 5 & $\begin{array}{l}\text { Profissional ligado à Saúde Suplementar, } \\
\text { atuou no PROCON por mais de } 10 \text { (dez) } \\
\text { anos }\end{array}$ & $\begin{array}{l}\text { Atua há mais de } 5 \text { (cinco) anos junto a } \\
\text { saúde suplementar }\end{array}$ \\
\hline 6 & $\begin{array}{l}\text { Gerente de Informação de Instituição ligada } \\
\text { ao Ministério da Saúde }\end{array}$ & $\begin{array}{l}\text { Atua junto a saúde suplementar há } \\
\text { mais de } 5 \text { (cinco) anos }\end{array}$ \\
\hline 7 & $\begin{array}{l}\text { Diretor-Adjunto de uma Instituição ligada } \\
\text { ao Ministério da Saúde }\end{array}$ & $\begin{array}{l}\text { Atua junto a saúde suplementar há } \\
\text { mais de } 5 \text { (cinco) anos }\end{array}$ \\
\hline 8 & $\begin{array}{l}\text { Secretário-Executivo de uma Instituição } \\
\text { ligada ao Ministério da Saúde }\end{array}$ & $\begin{array}{l}\text { Atua junto à saúde suplementar há } \\
\text { mais de } 10(\mathrm{dez}) \text { anos }\end{array}$ \\
\hline 9 & $\begin{array}{l}\text { Médico e Assessor-Chefe da Assessoria de } \\
\text { Informação em Saúde }\end{array}$ & $\begin{array}{l}\text { Atuou junto a saúde suplementar por } \\
\text { mais de } 5 \text { (cinco) anos }\end{array}$ \\
\hline 10 & Médico e Subsecretário de Atenção à Saúde & $\begin{array}{l}\text { Atuou junto a saúde suplementar por } \\
\text { mais de } 6 \text { (seis) anos }\end{array}$ \\
\hline 11 & Advogada e ex-diretora da ANS & $\begin{array}{l}\text { Atuou junto a saúde suplementar por } \\
\text { mais de } 7 \text { (sete) anos }\end{array}$ \\
\hline 12 & $\begin{array}{l}\text { Professora de Pós-Graduação do Curso de } \\
\text { Gestão em Saúde Suplementar }\end{array}$ & $\begin{array}{l}\text { Atua junto a saúde suplementar há } \\
\text { mais de } 5 \text { (cinco) anos }\end{array}$ \\
\hline
\end{tabular}


Todos os especialistas foram inicialmente contatados por telefone para explicação a respeito do projeto da pesquisa e para verificação de um e-mail válido para envio do questionário. Após este contato inicial, foi iniciada a primeira rodada de perguntas e as respostas foram analisadas e tabuladas para tratamento estatístico. Os entrevistados receberam na rodada seguinte o mesmo questionário com os resultados para reavaliação das respostas à luz da tabulação e das justificativas expressas pelos demais respondentes na rodada anterior. Esse processo foi repetido até que foi observado um consenso entre as informações e o resultado final determinado na segunda rodada.

$\mathrm{Na}$ segunda rodada, o questionário foi estruturado, havendo agregação de informações obtidas na rodada anterior. As respostas encontradas foram apresentadas e tabuladas, sendo questionada sua relevância. Também foi disponibilizado campo aberto para comentários.

Ainda na fase de coleta de dados, uma terceira etapa foi realizada onde se buscou realizar uma triangulação de dados. Foi utilizado o mesmo questionário em todas as rodadas da pesquisa, com mudança na sua forma de responder, como previsto na metodologia Delphi.

Para analisarmos os dados, valemo-nos da metodologia da análise de conteúdo (Bardin, 2008); isto é, preparamos e padronizamos os dados, os codificamos; posteriormente, os categorizamos, para que, finalmente, pudéssemos analisa-los.

As categorias de análise foram baseadas nos objetivos estratégicos da ANS já mencionados: a) Divulgação dos resultados para a sociedade; b) Intensificação do relacionamento com os públicos de interesse, inclusive o interno; c) Desenvolvimento de parcerias estratégicas para o incremento de projetos e pesquisas; d) Promoção da geração e disseminação de conhecimento no setor; e) Aprimoramento dos instrumentos e ferramentas de regulação; f) Aprimoramento da capacidade regulatória e g) Medição e ampliação da efetividade do uso das soluções de TI, e que irão servir para direcionar e organizar as análises dos resultados apresentados a seguir.

\section{REVELAÇÕES DO CAMPO E ANÁLISE DOS RESULTADOS}

A análise dos resultados foi desenvolvida seguindo a mesma lógica utilizada no questionário e, portanto, a apresentação foi organizada em oito blocos. $\mathrm{O}$ primeiro busca investigar junto aos especialistas os resultados alcançados pela sociedade após a criação da ANS e os mecanismos utilizados para divulgar estes resultados.

O segundo bloco visa explorar a percepção sobre os mecanismos utilizados pela ANS para intensificar o relacionamento com os públicos de interesse. $\mathrm{O}$ terceiro é destinado à análise do desenvolvimento de parcerias estratégicas para o incremento de projetos e pesquisas e como estas auxiliaram a atuação da ANS. O quarto bloco busca investigar se a ANS promove a geração e disseminação de conhecimento no setor de saúde suplementar e em que medida o público externo percebe esta atividade. $\mathrm{O}$ quinto tem a finalidade de analisar se a ANS tem aprimorado seus instrumentos e ferramentas de regulação e o que deveria ser feito para este aprimoramento. $\mathrm{O}$ sexto bloco visa analisar de que forma o aprimoramento da capacidade regulatória é percebido pela sociedade. O sétimo busca compreender se a ANS faz uso efetivo das soluções de TI e como pode melhorar o uso dessas soluções em prol da regulação do setor.

Finalmente, na última parte da análise apresentamos as tendências futuras para o setor e quais deveriam ser as ações da ANS no sentido de se preparar para atuar de maneira mais eficiente e transparente no tocante aos objetivos estratégicos referentes à Articulação e Aprimoramento Institucional. A referência de cada especialista foi colocada ao lado dos comentários.

\subsection{Resultados para a sociedade}

Sob o olhar dos especialistas, os resultados mais significativos, para a sociedade, após a criação da ANS, é transparência, conforme descritos nos fragmentos de discurso:

Regras claras na aquisição de planos de saúde. (E1)

A padronização das coberturas mínimas obrigatórias para os planos de saúde. $\mathrm{O}$ reajuste máximo permitido para os planos individuais. A fiscalização das operadoras de planos de saúde, exigindo maiores controles e consequentemente maior qualidade nos serviços prestados. (E7)

As seleções lexicais "regras claras" e "padronização" sinalizam benefícios para população, que são resultantes do maior controle sobre as operadoras de planos de saúde, qualidade de seus serviços, bem como a padronização das coberturas mínimas obrigatórias e os reajustes máximos permitidos para os planos individuais.

Também verificamos que a proibição às falhas de mercado observadas pelos Órgãos de Defesa do Consumidor, a normatização e um maior envolvimento da sociedade por meio das consultas e audiências públicas, possibilitadas pela Resolução Normativa 242 ANS (2010a), revelaram-se como ganhos para a sociedade, conforme se apreende dos seguintes fragmentos: 
Proibiu a rescisão dos contratos, exceto nos casos de fraude e inadimplência. Ou seja, diversas falhas de mercado, observadas pelos órgãos de defesa do consumidor foram proibidas pelas resoluções normativas da ANS. (E8)

Acho que o envolvimento da sociedade após a criação da ANS é muito maior (...) mediante a realização de consultas, audiências públicas e câmaras técnicas. (E11)

As seleções lexicais "falhas de mercado, observadas pelos órgãos de defesa do consumidor" e "o envolvimento da sociedade" refletem a importância da participação dos cidadãos no controle destas organizações.

Já no que tange a quais deveriam ser os meios de divulgação que a ANS deveria utilizar para divulgar os resultados da sua atuação, os especialistas afirmaram que deveriam ser utilizados os meios tradicionais de televisão e jornais, e a internet:

Um órgão com a responsabilidade da ANS deveria utilizar todos os meios de comunicação disponíveis. (E3)

(...) não se pode abrir mão da internet para a interação com a população. (E10)

Entretanto, a preocupação do alcance desses meios de comunicação também foi questionado; assim, foram sugeridas as realizações de palestras e seminários nos órgãos de defesa do consumidor, a fim de se encontrar alternativas para informar à população de baixa renda, a qual é a mais propensa a ser lesada. De fato, esta preocupação dos especialistas ficou patente conforme descrito a seguir:

Acredito que por meio de palestras e seminários em órgãos de defesa do consumo, universidades e escolas de ensino médio. (E6)

A ANS deveria ser mais atuante junto aos beneficiários de baixa renda, a mais lesada pelas operadoras de saúde. (E11)

As seleções lexicais "A ANS deveria ser mais atuante junto aos beneficiários de baixa renda" $\mathrm{e}$ "palestras e seminários" desvelaram diferentes percepções sobre os resultados alcançados pela sociedade com a criação da ANS; por um lado, houve ganhos no sentido de se ter regras mais claras, padronização, participação da sociedade e maior informação; por outro, explicitou que algumas camadas da população, especialmente os mais pobres e sem acesso aos meios de comunicação tradicionais, continuam sem informação sobre seus direitos com relação aos planos de saúde. Contudo, ao longo desta pesquisa, foi possível apreender as melhores formas de intensificar o relacionamento com os públicos de interesse da ANS, os quais são objeto do bloco a seguir.

\subsection{Intensificação do relacionamento com os públicos de interesse}

No Contrato de Gestão celebrado entre o Ministério da Saúde e a ANS (2014), a ação de intensificar o relacionamento com os públicos de interesse, inclusive o público interno, é reforçada como objetivo estratégico. A importância deste indicador é ressaltada pelos especialistas quando questionados sobre os melhores mecanismos para intensificar este relacionamento, conforme explicitado nos seguintes fragmentos de discurso:

No âmbito externo talvez seja o momento de realizar mais consultas públicas. (E4)

A integração da ANS com os mecanismos de atendimento à população é fundamental, especificamente os casos de saúde suplementar. (E9)

De fato, as seleções lexicais "talvez seja o momento de realizar mais consultas públicas" e "A integração da ANS com os mecanismos de atendimento à população é fundamental" sugerem que a ANS deveria aprofundar seu relacionamento com a sociedade e intensificar participação dos servidores nos regulamentos da Diretoria

Estas sugestões convergem com as ações da ANS de otimizar o relacionamento institucional com os Órgãos de Defesa do Consumidor (Programa Parceiros da Cidadania) previstas para 2013-2015 no Contrato de Gestão ANS (2014), mas que a rigor ainda não foram implementadas.

Ademais, ficou evidenciada a necessidade de a ANS estreitar seu relacionamento com seus públicos de interesse:

As redes sociais e a criação e disponibilização de aplicativo para smartphones e tablets que permitam contato direto com a ANS visando agilizar consultas e reclamações, gerando acompanhamento remoto em tempo real. (E11)

Essas falas permitem-nos inferir que os especialistas têm uma percepção apurada sobre a importância de se intensificar o relacionamento com os públicos de interesse, assim como a própria ANS também tem. Todavia, foi possível apreender que o discurso não reflete a prática nas ações da ANS, visto que, apesar de estarem previstas ações no planejamento (Contrato de Gestão, 2014), sua implantação não vem sendo realizada. 


\subsection{Desenvolver parcerias estratégicas para projetos e pesquisas}

Com relação ao desenvolvimento de parcerias estratégicas para o incremento de projetos e pesquisas e como estas auxiliaram a atuação da ANS, um dos especialistas asseverou que: “...Essas parcerias auxiliam a ANS em vários aspectos, pois trazem uma visão diferenciada no processo de trabalho, da forma como encarar os desafios da regulação". (E3). Neste depoimento, fica patente a posição de que as parcerias estratégicas constituem uma ferramenta importante no desenvolvimento da atividade regulatória, que deve ser enxergada por diversos pontos de vista. Foi possível verificar que há uma relação entre as parcerias e a construção do futuro e das tendências para a regulação, o que fica explicitado no fragmento a seguir:

Elas apoiam no presente as ações da ANS e registram para o futuro o caminho percorrido pelos órgãos reguladores, constituindo um registro histórico. (E4)

Contudo, persevera uma disfunção na atuação da ANS que privilegia as relações com as empresas clientes e com as operadoras de saúde, deixando em segundo plano os consumidores finais:

As parcerias existem, mas cabe uma posição mais crítica sobre a atuação da ANS, pois a agência tem fortalecido a relação entre o intermediário, empresa, associação ou sindicato, e as operadoras, enfraquecendo a proteção ao consumidor final, que é o verdadeiro beneficiário do plano. Isso porque o funcionário da empresa financia o plano, mesmo que indiretamente. (E11).

A seleção lexical "enfraquecendo o consumidor final" aponta para a necessidade de a ANS focar, efetivamente, na qualidade dos serviços prestados aos cidadãos, e não atuar como agente de proteção às empresas.

\subsection{Promover a geração e disseminação de conhecimento no setor}

No que se refere ao aspecto da promoção e disseminação de conhecimentos no setor de saúde, identificamos uma divisão nas percepções, visto que na visão de uma parte dos especialistas a ANS está gerando e disseminando conhecimento, como afirma categoricamente o depoimento a seguir: "Claro que sim! O caderno de informação da ANS é amplamente utilizado pelos meios acadêmicos, pelos institutos de estudos e pesquisas públicos e privados” (E3). Esta visão é reforçada pelo fragmento seguinte, que enumera as ações que a agência vem desenvolvendo para disseminar o conhecimento no setor de saúde.
Os seminários que a ANS promove, as câmaras técnicas, consultas públicas, eventos nacionais e internacionais, as cartilhas de bolso (E9) (...) tudo isso está atuando para que esse processo de disseminação do conhecimento seja expandido. (E6)

Porém, foi possível apreender pela fala de um especialista que "Ainda há um caminho enorme a percorrer para diminuição da assimetria de informação na saúde suplementar, mas a ANS vem trabalhando fortemente para isso". (E4)

Os especialistas reconhecem a existência de ferramentas de geração e disseminação de conhecimento, conforme explicitado nos seguintes fragmentos de discurso

(...) Os mecanismos de participação social não tem efetividade. A Câmara de Saúde Suplementar não tem influência nas decisões só é informada depois que já foram tomadas. (E11)

Os públicos são bastante heterogêneos. (...) os de menor poder aquisitivo e com menos escolaridade não entendem as informações que chegam. (E5)

Entretanto, as seleções lexicais "Os mecanismos de participação social não tem efetividade" e "A Câmara de Saúde Suplementar não tem influência nas decisões só é informada depois que já foram tomadas" sugerem que as ferramentas supracitadas não são efetivas em atender às demandas dos usuários dos planos de saúde, nomeadamente os de poder aquisitivo mais baixo (fala do especialista 5).

Esta mesma percepção foi retificada por outro especialista, que afirmou que:

A ANS tem de ser popular. Da forma que está, estes que são a parte mais fraca nessa relação, não são ouvidos. (E9)

Este fragmento de discurso reitera a necessidade de que o sistema de disseminação do conhecimento adotado pela ANS deveria ser mais eficaz, e atender amplamente às demandas de todos os participantes do mercado de maneira igualitária.

\subsection{Aprimorar os instrumentos e ferramentas de regulação}

Nessa categoria, foram encontradas revelações demonstrando uma percepção negativa sobre os aspectos ligados ao aprimoramento dos instrumentos de regulação por parte da ANS que, de acordo com o extrato a seguir: “(...) ainda está em processo de adaptação. Muitos mecanismos de regulamentação $e$ fiscalização foram desenvolvidos nesse período, beneficiando a sociedade e todo o mercado. Ocorre 
que a Agência ainda apresenta falhas, como: publicação de Resolução Normativa em um dia $e$ alteração em menos de uma semana”. (E7).

Ainda com relação às ferramentas de regulação, a percepção dos especialistas mostra de maneira categórica que a agência não vem aprimorando instrumentos e ferramentas de regulação, e que existem diversas disfunções presentes no mercado de saúde suplementar, conforme fica patente no fragmento a seguir:

Não. Constato nas ações que acompanho que o consumidor enfrenta dificuldade para adquirir plano de saúde individual por falhas de regulação da ANS. Outro ponto é a ausência de seguro para pessoas físicas em detrimento dos planos coletivos e por adesão. Os reajustes dos planos individuais são estipulados pelo governo uma vez por ano, já os jurídicos são negociados entre as partes. (E11)

Já no tocante ao que deveria ser feito para aprimorar os instrumentos de regulação dos serviços de saúde suplementar, o fragmento a seguir vem desvelar que de fato a questão não está nos instrumentos utilizados, mas sim nas relações interpessoais e nos conflitos de interesse presentes no setor:

No meu entender, o intercâmbio de profissionais do mercado e da agência deveria ser proibido. Há muitos casos de diretores que são da iniciativa privada, trabalham por um tempo na ANS e voltam a trabalhar nas operadoras após passar pela agência, comprometendo a autonomia da regulação. (E10)

Mais uma vez, neste fragmento de discurso, é denunciada a instrumentalização da ANS como defensora dos interesses de empresas e formadora de profissionais, profundo conhecedores das regras, para as mesmas. A seleção lexical "No meu entender o intercâmbio de profissionais do mercado e da agência deveria ser proibido" sugere que caberia uma nova regra que estipulasse um período de carência profissional, o que já existe em algumas esferas do serviço público.

\subsection{Aprimorar a capacidade regulatória}

Outro aspecto abordado pela pesquisa que merece destaque é a respeito da forma pela qual o aprimoramento da capacidade regulatória é percebida pela sociedade Nesse quesito, a visão dos especialistas aponta para um desequilíbrio na mediação dos conflitos entre os médicos e as operadoras de saúde, como fica patente no fragmento a seguir:
Com relação aos médicos, fica a sensação de que a capacidade regulatória está desequilibrada sempre para o lado das operadoras, já que os médicos vem tornando pública sua posição contrária à Resolução Normativa expressa na Consulta Pública 54/2013, que não contemplou as demandas sobre contratualização. Para a sociedade fica claro que a ANS foge do seu dever legal de mediar os conflitos entre operadoras e médicos da Saúde Suplementar, não produzindo a necessária segurança jurídica que se daria através de uma real contratualização. (E10)

De maneira complementar, no depoimento seguinte fica desvelado o comprometimento da isonomia no atendimento à sociedade, uma vez que há claro benefício a quem possui planos de saúde mais caros, em prejuízo dos clientes de operadoras menores que não são obrigadas a ampliar os canais de comunicação com os clientes:

$\mathrm{Na}$ minha visão, as novas regras da ANS criadas pela Resolução Normativa 395 para planos de saúde são bastante problemáticas para a sociedade, já que obriga apenas as grandes operadoras a disponibilizar canais de contato presencial e telefônico 24 horas por dia, 7 dias por semana. No entanto, desobriga as médias e pequenas empresas até em relação à necessidade de atendimento aos usuários via call center, ou seja, estas regras só atendem a quem tem os planos mais caros dos portfólios das operadoras e não atendem aos clientes de planos menores, que mais uma vez foram desconsiderados". (E11)

\subsection{Medir e ampliar a efetividade do uso das soluções de TI}

O uso das soluções de tecnologia da informação vem sendo considerado estratégico para a atuação da ANS desde sua criação, tendo sua importância reiterada através do contrato de gestão ANS (2014). No entanto, os achados da pesquisa não revelam unanimidade a respeito da efetividade desta utilização das soluções de TI em prol da regulação do setor.

O controle de indicadores técnicos e de mercado é citado como ponto positivo da utilização da TI pela agência e aparece representado pelo depoimento a seguir:

Sim. Um exemplo disso é a obrigatoriedade de envio dos aplicativos SIP (Sistema de Informação de Produto), SIB (Sistema de Informação de Beneficiários) e DIOPS (Documento de Informações Periódicas). Com base nas informações enviadas por meio desses aplicativos, a ANS 
consegue perceber, se o número médio de consultas por beneficiário/ano da operadora está aquém do mercado. (E7)

Contudo, os dados revelam que há questões que influenciam indiretamente a efetividade das soluções de TI, sendo que o primeiro aspecto citado ressalta a importância da definição de processos e o segundo aponta para a escassez de recursos disponíveis:

No caso da ANS, o problema se dá na definição dos processos de trabalho. A agência carece de falta de formalização dos processos de trabalho entre a Gerência-Geral e as demais Gerências, onde os processos não são mapeados e ocorre redundância de trabalho. (E10)

Há limitação de recursos financeiros, de recursos humanos, restrições orçamentárias para capacitações e contingenciamento do Governo Federal, gerando inclusive a possibilidade de incidentes de segurança da informação. (E12)

Neste caso, é possível inferir que a ANS parece carecer muito mais de um redesenho de processos e melhor gerenciamento dos recursos humanos $\mathrm{e}$ financeiros para alcançar a maior efetividade no uso das ferramentas de TI.

Ainda sobre como a ANS pode melhorar o uso das soluções de TI em prol da regulação do setor, o seguinte depoimento aponta caminhos como:

Reduzindo a burocracia nos processos, acompanhando e monitorando os conflitos entre as áreas e o setor de TI, modificando a priorização de projetos não motivados por argumentos técnicos. (E3)

\subsection{Tendências, Eficiência e Transparência}

Aqui buscamos investigar a percepção dos especialistas sobre as tendências futuras para o setor de saúde suplementar, tendo em vista a evolução da demanda do mercado, a atuação das operadoras e a atuação da ANS. Os depoimentos demonstram preocupação com o futuro da relação entre a oferta dos serviços frente à demanda crescente e com a concentração e eventual cartelização do setor de saúde suplementar, conforme segue:

(...) vejo a necessidade de se regular a venda de planos, compatível com a capacidade instalada existente, como já aconteceu no setor de telefonia. (E1)

(...) a concentração em poucas empresas e a redução de custos implantada pelas empresas podem gerar distorções que precisam ser combatidas pela ANS e pelo CADE. (E2)

Outra revelação dos dados que se fez presente foi em relação à qualidade do serviço prestado no futuro, uma vez que o SUS não dá conta da demanda, como assevera o fragmento a seguir:

Percebe-se uma deterioração dos Sistemas de Saúde Pública e parece que este é um caminho sem volta. Portanto, mais e mais pessoas terão que buscar os planos de saúde nos próximos anos, e a ANS terá o desafio de buscar através da regulação, evitar o colapso do sistema e as principais disfunções presentes em outros setores, como cartéis, corrupção, conluios e queda na qualidade do serviço prestado. (E10)

Além disso, durante a análise dos dados sobre quais deveriam ser as ações da ANS no sentido de se tornar mais eficiente e transparente no tocante aos objetivos estratégicos de Articulação e Aprimoramento Institucional, foi possível perceber que a agência terá grandes desafios a enfrentar, como pode ser apreendido na seguinte fala:

A eficiência certamente está ligada a um trabalho de redesenho de processos, reduzindo burocracia e intensificando os sistemas de TI implantados na ANS. Já a transparência dependerá do quanto a agência terá a coragem necessária para enfrentar, regular, multar, descredenciar e informar à sociedade sobre a atuação, muitas vezes dolosa, das operadoras de saúde suplementar. (E10)

\section{CONCLUSÕES}

O objetivo deste estudo foi analisar em que medida a ANS tem alcançado os objetivos traçados no momento da sua criação, especialmente no tocante ao eixo estratégico de aprimoramento e articulação institucional. Sua relevância jaz no fato de as agências reguladoras estarem passando por uma fase de refinamento de seu papel na sociedade e no modelo de governo e reforma do Estado, e são bastante questionadas em sua função de regular os setores privatizados nas décadas recentes.

Os resultados da pesquisa permitiram-nos avaliar o desenvolvimento das relações com os públicos de interesse; a transparência na divulgação de informações concernentes ao setor; o aprimoramento da capacidade regulatória, além de descrever as ferramentas e mecanismos utilizados como facilitadores dos objetivos da agência, oferecendo à sociedade uma regulação mais elaborada, refinada e que, apesar de todos os percalços e necessidade de 
amadurecimento, vem cumprindo as premissas básicas dispostas na lei e em seus eixos institucionais.

Ademais, ficou evidente que a ANS atua em um mercado complexo, com interações fortes e com grande apelo político e econômico; entretanto, ações como a criação do rol mínimo de procedimentos e a diminuição de assimetria de informações no setor, dentre outras, poderão delimitar e reforçar sua importância na equalização das forças entre os atores da saúde suplementar, evitando que elos mais fracos sucumbam ao poder dos mais fortes.

Se, por um lado, a atuação da ANS beneficiou a sociedade em geral, nomeadamente, no que diz respeito a um maior controle sobre as operadoras de planos de saúde, qualidade de seus serviços, bem como a padronização das coberturas mínimas obrigatórias e os reajustes máximos permitidos para os planos individuais; por outro, há ainda espaço para melhoria. Este diagnóstico é a grande contribuição desta pesquisa para a organização em questão.

Sob a ótica dos especialistas, os planos de saúde não levam multas por falta de agilidade da ANS em analisar e julgar as reclamações; portanto a organização deve investir no mapeamento de seus processos, visando a ficar mais eficiente.

$\mathrm{Na}$ visão dos nossos interlocutores, a ANS precisa também intensificar sua comunicação com a sociedade, principalmente a população de baixa renda. Também ficou evidenciado que, na opinião destes indivíduos, as agências reguladoras, criadas para fiscalizar e proteger os interesses dos beneficiários e clientes dos planos de saúde, no final acabam protegendo as empresas operadoras que prestam maus serviços. Por isso, sugerimos que seja estipulado um período de quarentena, como já ocorre em outros órgãos públicos, para os profissionais que lá tenham trabalhado, evitando, assim, que os mesmos sejam imediatamente contratados pelos planos de saúde, e levem consigo informações estratégicas.

Apesar de sua relevância, este estudo também apresenta limitações, principalmente o fato de não termos ouvido a sociedade, os beneficiários e os servidores públicos. Esta triangulação nos permitiria validar os resultados de nossa pesquisa. Portanto, esta é a nossa proposta para estudos futuros: que se realizem pesquisas com esses outros atores, ou ainda, que se replique esta pesquisa para outros eixos estratégicos da ANS.

\section{REFERÊNCIAS}

ANS. (2004) Regulação \& Saúde. v. 3. Rio de Janeiro: Documentos Técnicos de Apoio ao Fórum de Saúde Suplementar de 2003.

ANS. (2010b) Programa de Qualificação da Saúde Suplementar. Rio de Janeiro: ANS.
ANS. (2010a) Caderno de Informação de Saúde Suplementar: Beneficiários, Operadoras e Planos. (Março/2011). Rio de Janeiro: ANS.

ANS. (2014). Contrato de Gestão. Disponível em http://www.ans.gov.br/aans/transparenciainstitucional. Acesso em 23 fev. 2016.

Avelar, Lúcia; Cintra, Antônio. (2004). O Sistema Político Brasileiro: Uma Introdução. $2^{\mathrm{a}}$ Ed. São Paulo: Editora Unesp.

Bardin, Laurence. (2008). Análise de conteúdo. $4^{\mathrm{a}}$ Edição, Lisboa: Edições 70.

BRASIL. (1995). Plano Diretor da Reforma do Aparelho do Estado. Brasília: Presidência da República.

BRASIL. (2007). Regulação em Saúde. Brasília: Conselho Nacional de Secretários de Saúde (CONASS),

Bresser-Pereira, Luís Carlos. (1996). Da administração pública burocrática à gerencial. Revista do Serviço Público, v. 47, n. 1, p. 7-40.

Boschi, Renato R. (2002). O Estado e o Setor Privado no Cenário Pós-Reformas: Novas Modalidades de Regulação. Buenos Aires. IUPERJ.

Castro, Janice D. (2002). Regulação em saúde: análise de conceitos fundamentais. Sociologias, v. 7, n. 7.

Costa, Nilson R. (2008). O regime regulatório e o mercado de planos de saúde no Brasil. Ciência \& Saúde Coletiva, v. 13, n. 5, p. 1453-1462.

Delurgio, Stephen A. (1998). Forecasting principles and applications. Singapura: McGraw-Hill.

Filardi, Fernando. (2000). Os primeiros resultados do novo modelo de regulação do setor elétrico: a experiência da Light Serviços de Eletricidade S.A. Revista de Administração Pública, v. 34, n. 2, p. 1-10.

Goldfinch, Shaun; Wallis, Joe. (2010). Two myths of convergence in public management reform, Public Administration Review, v. 88, n. 4, p. 1099-1115.

Ibañez, Nelson; Vecina Neto, Gonzalo. (2007). Modelos de gestão e o SUS. Revista Ciência \& Saúde Coletiva, v. 12.

Lei $\quad \mathrm{N}^{\mathrm{o}} \quad 9.656 . \quad$ Disponível em http://www.planalto.gov.br/ccivil_03/LEIS/ Acesso em 23 fev. 2016. 
Quinze Anos da Agência Nacional de Saúde (ANS): Análise do Eixo Estratégico de Articulação e Aprimoramento Institucional na Percepção dos Especialistas

Lei $\quad \mathrm{N}^{\circ} \quad 9.961$ Disponível em http://www.ans.gov.br/portal/site/legislacao/legislac ao_. Acesso em 26 jan. 2010.

Nitão, Samara. (2004). V. Saúde Suplementar no Brasil: Um Estudo da Dinâmica Industrial PósRegulamentação. Rio de Janeiro. Dissertação (Mestrado) - Escola Nacional de Saúde Pública Sérgio Arouca da Fundação Oswaldo Cruz, Rio de Janeiro.

Ocké-Reis Carlos O. (2005). Uma reflexão sobre o papel da ANS em defesa do interesse público. Revista de Administração Pública, v. 39, n. 6, p. 1303-17.

Pinheiro, Ivan A.; Monteggia, Ediane G.; Aguzzoli, Roberta L. (2000). Agências Autônomas de Regulação: mudanças à vista no relacionamento Estado $\mathrm{x}$ setor privado $\mathrm{x}$ sociedade. In: ENANPAD 24, 2000, Florianópolis; Anais...Florianópolis: ANPAD.
Salvatori, Rachel T.; Ventura, Carla A. (2012). A agência nacional de saúde suplementar - ANS: onze anos de regulação dos planos de saúde. Organizações \& Sociedade, v. 19, n. 62, p. 471487.

Santos, Fausto P.; Malta, Deborah C.; Merhy, Emerson E. (2008). A regulação na saúde suplementar: uma análise dos principais resultados alcançados. Ciência \& Saúde Coletiva, v. 13, n. 5, p. 1463 1475.

Souza, Antônio R. (2004). As Agências Reguladoras de Serviços Públicos e Campo Organizacional: Limites e Possibilidades. Rio de Janeiro.

Wright, James T.C.; Giovinazzo, Renata A. (2000). Delphi. Uma ferramenta de apoio ao planejamento prospectivo. Caderno de Pesquisas em Administração, São Paulo, v. 1, n. 12, $2^{\circ}$ trim. 